\title{
Integrated Information System for reserving rooms in Hotels
}

\author{
Dr. Safarini Osama \\ IT Department \\ University of Tabuk, \\ Tabuk, KSA \\ usama.safarini@gmail.com
}

\begin{abstract}
It is very important to build new and modern flexible dynamic effective compatible reusable information systems including database to help manipulate different processes and deal with many parts around it. One of these is managing the room reservations for groups and individual, to focus necessary needs in hotels and to be integrated with accounting system. This system provides many tools can be used in taking decision.
\end{abstract}

Keywords: IS - Information System; MIS -Management Information System; DFD - Data Flow Diagram; ER- Entity Relationship; DBMS - Database Management system.

\section{INTRODUCTION}

Since tourism is now taking advantage in all over the world, so the role of hotels is coming greater than before, from this point of view our system gains its importance. We had followed the standards of building an information system [1], which is analysis, design, and implementation.

Hotels are big organizations that take place in the market, so using manual system may lead to more and more errors, because people forgot, and their thinking is limited, so we think that using a computerized system is more efficient, especially that we are living in information age.

Reservation is the most important part of any hotel system, this process should be efficient. So it can serve the commercial goals of the hotel. The most important entity in the Reservation process is the Rooms, reserving Rooms in a hotel should be dynamic, and the whole process should be done in an effective way to maximize the hotel profits.

We have two types of customers in the hotel; individual customers and group customers, and the person who is responsible for reservation is the front office manager. Group customers have higher priority over individual customers in high season, because group customers are more stable. So the front office manager should take decisions about the reservation, these decisions can be supported by the computerized system. This system provides many tools that the front office manager could use in taking his decision for allocating rooms and reserve for groups and taking right decisions.

Note that this system can't operate alone in the hotel, because it concentrates mainly in reservation process, the system needs an accounting system and a management information system, and so it can serve all the needs of the hotel.

We have tried to make it possible to connect our system to other systems (Accounting, MIS) though two screens which are; Accounting screen which deals with entering bills for a customer, and recipient screen which deals with adding a recipient for the hotel. A very important part that we include in our system is the report generator, which enables the manager to have any information about the customers in the hotel. We tried to improve the reusability of our system through setting screen which lets the user change the main settings such as name of the hotel, colors of the background of the screens, and hotel logo.

\section{A. Similar Projects}

\section{1) Fidelio Hotel System}

One of the most famous hotels systems is Fidelio, which was developed by Microsoft; it can be considered as a complete hotel system, since it has a hotel accounting system and a management information system in addition to reservation system. It was developed in 1988, but in those days' computers was in its first stages to the commercial business and big organizations, so Fidelio wasn't famous at his first appearance. Over and over when computers take place in the market, big organizations such as hotels start using computerized systems, and then Fidelio starts to be famous.

Fidelio reservation system divides the reservation process into two types, Group and Individual reservation. Both the recipient and the reservation manager can reserve for any type. The reservation information and resident information are entered from the same screen.

When allocating rooms for customers in hotel, you can click on allocate button to show a small screen containing the empty rooms. In other words you can fill all information for customers in the same screen whether this customer was an individual customer or a group customer. As for accounting, you enter other screens to add the customer bills, this screen contains a list of valued facilities, and you can change the cost from this screen. There is no ability in Fidelio to change the color of the screen or the fonts, also the name of hotel in not shown in the main screen.

Fidelio Reservation System contains some static reports about the customers in hotel. These reports contain static data 
about customers such as full name and room numbers. You cannot change it by removing or adding new fields.

The user can change his password and nickname from the system that the reservation manager gave it to him. The system doesn't provide the manager with any kind of statistics about the situation of the rooms in the hotel. A reservation manager screen contains two main components. The first is adding recipient information and assign him a shift and submanager property. The second component is adding new room to hotel and converts an existing room to maintenance state.

\section{DISCUSSION}

The designed Information system begins with a login screen Fig.1

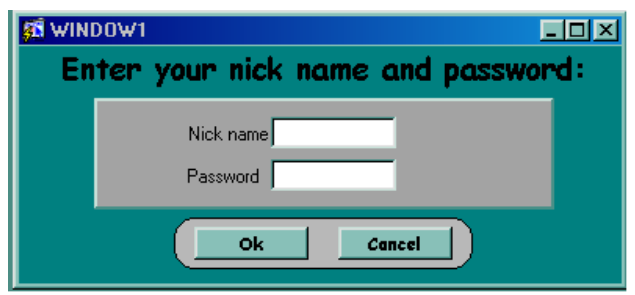

Fig.1 Login Screen

This screen is the first screen in the system which allows the authorized user to access the system. Our project is talking mainly about the reservation process, and components needed to connect the reservation system with other systems needed by the hotel.

First, we divide the reservation process into two types, which are group's reservation and individual's reservation, this division was done so the user will not be confused, and the information needed from each entity differ from the other.

The reservation process is provided with search capabilities, allocating rooms for the customer is one of the most important components of the system which enables the front office manager and recipient to allocate empty rooms for the customers. The Main menu is illustrated in fig. 2

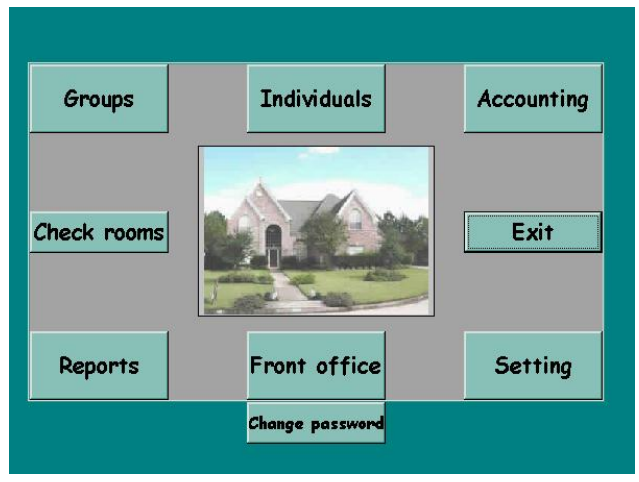

Fig.2 Main Screen

A. The setting screen:

This screen allows the user to modify some settings such as the color and the hotel name and the hotel's logo (see fig3.)

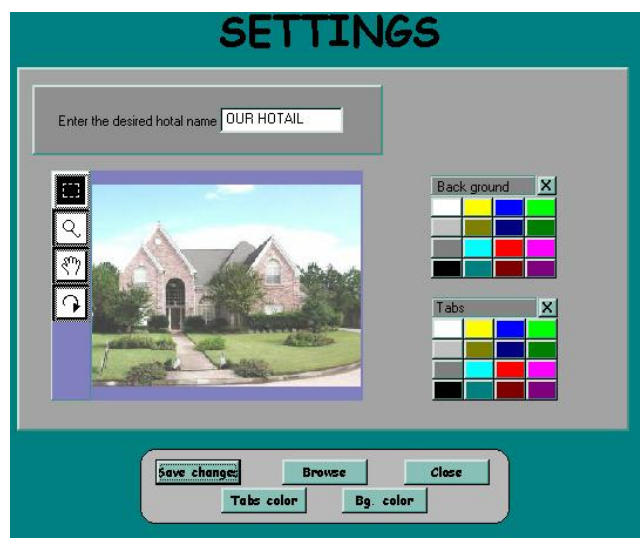

Fig. 3 Settings Screen

\section{B. Chart Screen (fig. 4)}

This screen allow the user to enter only the date from a certain date to a certain date, then by pressing the 'View' button it will give the user a pie chart showing him the every type rooms in the hotel and its partition comparing with other room types.

The user will get also some additional numeric data.

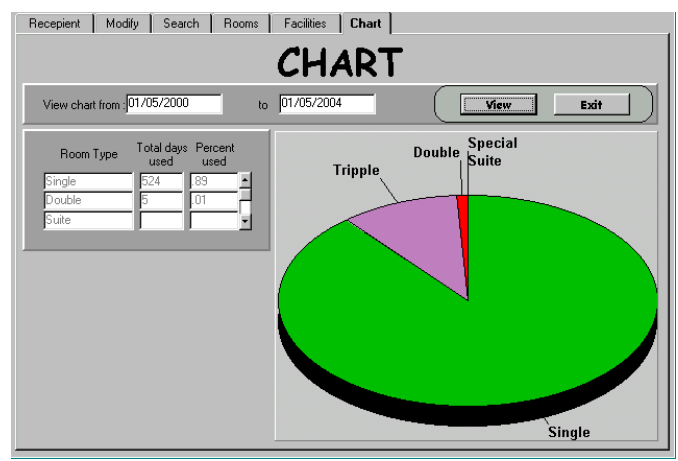

Fig.4 Chart Screen

\section{System Design and Implementation}

We have tried to follow the standard phases of building a system, and our main aim is to design a user friendly system interface that helps users to finish their work in an efficient way and the lowest effort, also we tried to add many features and functions to ease the work process. Hotel systems contain a dynamic decision for the work to be finished, so we tried to divide the project into entities according to DFD (data flow diagram). We choose tab page design so the user will feel comfort with working with the system.

\section{The Accounting System}

The system does not include the accounting features in a detailed way, because hotels have its own systems that deal with accounting perspective. But in our analysis for the system we found that some models should be involved in the reservation system in order to connect this system with the accounting system of the hotel.

The most important model for doing what mentioned 
above is the customer accounts, and enabling the recipient to add bills (fig.5) for the customers depending on their room's numbers.

We made a single screen for adding bills to the customers, the recipient take the bill and choose one facility form the hotel facilities, and enter the amount of the bill, all what he have to do is to give the customer room number, also he can print a bill for the customer at any time while the customer is in the hotel.

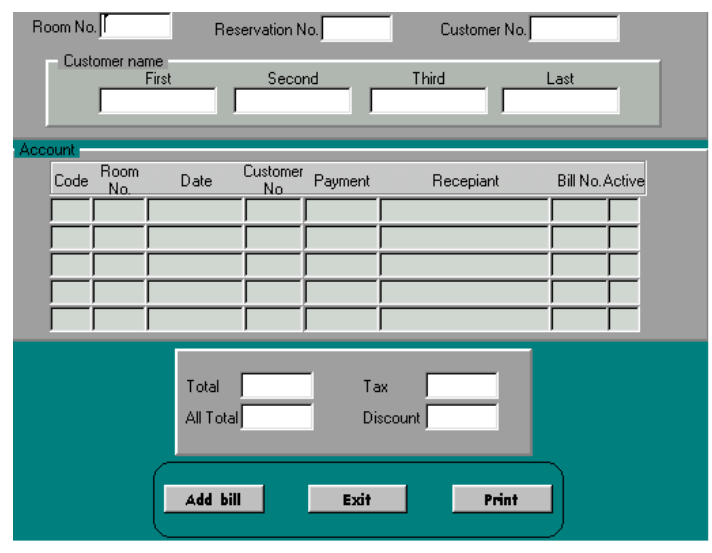

Fig. 5 Accounting Screen

\section{E. Reports}

The reports are considered as a very important component of any system, so we define two categories of reports, which are; static reports and generated reports.

Since the manager takes place in taking decision in the hotel, and the reports is one of the most important tools that enable him to do that, so we concentrate on this component. There is a static report on each screen; we tried to put the most common report on each tab page for every screen. Also we design a report generator that enables the user to have dynamic reports types and control the data to be included in the report.

Our concentration on the reports is for the following reasons;

- The reports is an essential part of any system,

- Helps the managers to take decision about the hotel

- $\quad$ Ease the process of retrieving information about the customers in the group and also the groups.

\section{F. Implementation Decision}

We intended to use Oracle8 [2] and Developer6 which include Forms6i and Report6i; we thought that it's powerful for implementing the proposed system.

Oracle contains many features that make it over choice for implementing the project. The main features are:

1) Oracle is a database Management System, which helps in implementation of enterprise systems.

2) Oracle supports a stable database with minimum percentage of crash.

3) It helps in designing powerful database tables and schemes.
Also, the packages included in Oracle [3], such as Form Builder and Report Builder provides good GUI tools in order to ease the process of prototyping and designing interfaces in a user-friendly manner [4]. We had used ER diagram for database design fig. 6 , because it is powerful tool for database design [5] and scheme elicitation.

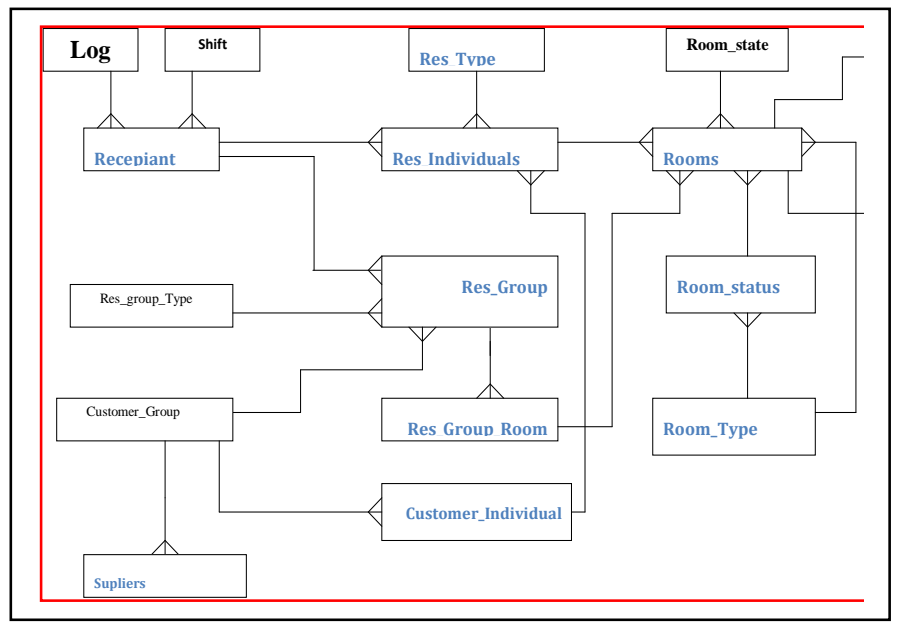

Fig. 6 ER diagram

\section{G. System Features}

1) Fast and Easy to use

From a system point of view nothing is more important to the quality of direct customer service (reservations, checkin/out etc.) than speed and accuracy of response. Our hotel system challenges overcome all other hotel systems in speed and in ease of use.

\section{2) Flexible Reservation and Enquiry Procedure}

As much or as little information that any Enquirer offers can be entered in whatever orders it is given. As soon as the name is entered, be it a previous guest or Enquirer, a corporate contact or travel agent, a search will rapidly present their details including e.g. negotiated rates and preferred room numbers. The speed of this name search is of critical importance if it is to be effective - firstly as an aid to prompt customer service and recognition and secondly to ensure the growth of a 'clean' accurate database without record duplication. Our hotel fulfills these criteria.

\section{3) Automatic Report Generator}

For any needed Enquirer, simply enter their date and make some choices to have quickly and accurately completed in front of your eyes a report automatically created. The benefits are faster customer service, accurate information and reduced mailing costs. (No special hardware, only a standard PC is required).

\section{4) On-Screen Room Chart}

The Room Chart provides availability and occupancy information in a familiar format for those transferring from a manual front office system. Our system is designed to be as friendly and familiar to the first-time computer user as possible, which also makes re-training for experienced users relatively quick and easy. 


\section{5) Accounts}

The majority of data transfer to accounts is usually between the front office (facility) and the accounting, which are totally integrated with our hotel. Finally our hotel System hopes to provide Travelogue Hotels and Resorts with faster and better guest service, including up-to-date history information. The system can provide increased revenues through tighter database control, as well as forecasting data and reports to help make smarter management decisions.

\section{6) The Front Office Features}

Front office gives the user the ability to enter recipient employees and give them their nick-names and passwords, which can be changed by the recipient later on. Also the search ability for recipients is available.

For new rooms its cost, type, and number can be done through the front office. To add new facility and its cost, can be done through the front office. There is the ability to modify the discount rate and the tax percentage.

Also in the front office there is the ability to the user to view a semi analysis on the usability of the rooms according to a given period of time, it views the data at two statistical ways the first one graphical way by showing a pie chart for rooms for specified type, the second one by showing a table with accurate number for rooms.

\section{CONCLUSION}

\section{A. Comparison with Fidelio System}

As we mentioned before, Fidelio is a complete hotel system, which deals with accounting and management information systems, in addition of reservation system. So our comparison, as shown in the following table 1, will be between over system and Fidelio reservation system.

As a main conclusion is the efficiency in generating reports, friendly user interfaces, making decision, enough stable system as we intended to use Oracle8 and Developer6. Previously discussed system features can be considered as conclusions.

\section{B. Future Scope}

The future plans are to get our developed information system more integrated with Accounting and Management systems.

\section{REFERENCES}

[1] Principles of Information Systems, 10th Edition, Ralph M. Stair, George Reynolds; ISBN-10: 0538478292 ISBN-13: 9780538478298, 704 Pages CB $\odot 2012$ Published

[2] Mastering Oracle PL/SQL: Practical Solutions Copyright @ 2004 by Connor McDonald, with Chaim Katz, Christopher Beck, Joel R. Kallman, and David C. Knox, ISBN (pbk): 1-59059-217-4

[3] Oracle_Database_10g_-_The_Complete_Reference_ _McGraw_Hill_Osborne.pdf 7935 http://rapidshare.com/files/11822933...11_Osborne.pdf

$\mathrm{KB}$

4] Programming with Microsoft Visual Basic 6.0: an object-oriented approach : comprehensive, Edition illustrated; Michael V. Ekedahl, William Arthur Newman; Course Technology, 1999 - 720 pages; ISBN 0760010765, 9780760010761.

[5] Database Design for Mere Mortals®: A Hands-On Guide to Relational Database Design (2nd Edition) [Paperback] 611 pages, Michael J.
Hernandez Publisher: Addison-Wesley Professional; 2 edition (March 13, 2003) ISBN-10: 0201752840 ISBN-13: 978-0201752847.

[6] Dhindsa, K. S. (2011). Modelling \& Designing Land Record Information System Using Unified Modelling Language. IJACSA International Journal of Advanced Computer Science and Applications, $2(2), 26-30$.

TABLE 1 COMPARISON BETWEEN OUR SYSTEM WITH FIDELIO SYSTEM

\begin{tabular}{|c|c|c|}
\hline $\begin{array}{l}\text { SYSTEM } \\
\text { ITEM }\end{array}$ & Our System & Fidelio System \\
\hline $\begin{array}{c}\text { Group } \\
\text { Reservation }\end{array}$ & $\begin{array}{l}\text { Separate screen for } \\
\text { reserving hotel for a } \\
\text { group }\end{array}$ & $\begin{array}{l}\text { Reserve using } \\
\text { reservation screen }\end{array}$ \\
\hline $\begin{array}{l}\text { Individual } \\
\text { Reservation }\end{array}$ & $\begin{array}{l}\text { Separate screen for } \\
\text { reserving hotel for an } \\
\text { individual }\end{array}$ & $\begin{array}{l}\text { Reserve using } \\
\text { reservation screen }\end{array}$ \\
\hline $\begin{array}{l}\text { Allocating } \\
\text { Rooms }\end{array}$ & $\begin{array}{l}\text { Two screens one } \\
\text { for the groups and } \\
\text { one for the } \\
\text { individuals, dynamic } \\
\text { search according to } \\
\text { check in and check } \\
\text { out date. }\end{array}$ & $\begin{array}{l}\text { One allocating screen } \\
\text { shows the empty } \\
\text { rooms, not dynamic, } \\
\text { working parallel with } \\
\text { manual system }\end{array}$ \\
\hline Search & $\begin{array}{l}\text { Every screen has } \\
\text { search capability for a } \\
\text { customer or group } \\
\text { and its customers, } \\
\text { able to search by } \\
\text { name, room number, } \\
\text { date, group or name. }\end{array}$ & $\begin{array}{l}\text { Search for customers } \\
\text { by their names or } \\
\text { room numbers. }\end{array}$ \\
\hline Settings & $\begin{array}{l}\text { Able to change screen } \\
\text { colors, hotel logo, } \\
\text { and hotel name. }\end{array}$ & "No settings" \\
\hline Reports & \begin{tabular}{lr}
\multicolumn{3}{l}{ Static reports on each } \\
screen and a report \\
generator \\
individuals \\
groups.
\end{tabular} & $\begin{array}{l}\text { Four static reports on } \\
\text { reservation screen. }\end{array}$ \\
\hline $\begin{array}{l}\text { Front Office } \\
\text { Manager }\end{array}$ & $\begin{array}{l}\text { Provide a screen with } \\
\text { ability to add a } \\
\text { recipient, room, } \\
\text { facility, and charts } \\
\text { about the hotel status. }\end{array}$ & $\begin{array}{l}\text { Screen for adding } \\
\text { new rooms and its } \\
\text { status. }\end{array}$ \\
\hline
\end{tabular}

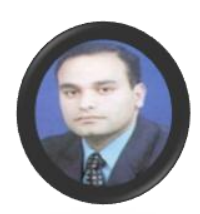

AUTHORS PROFILE

Dr. Osama Ahmad Salim Safarini had finished his $\mathrm{PhD}$. from The Russian State University of Oil and Gaz Named after J. M. Gudkin, Moscow, 2000, at a Computerized-Control Systems Department.

He obtained his BSC and MSC in Engineering and Computing Science from Odessa Polytechnic National State University in Ukraine 1996. He worked in different universities and 
countries. His research is concentrated on Automation in different branches. 